\title{
Post Prandial Hyperglycemia: A Real Threat for Patients with Type 2 Diabetes Mellitus
}

\author{
Arif Faruqui \\ 504A, Opp. K.B. Bhabha Hospital, Waterfield Road, Bandra (W), Mumbai-400050, Maharashtra, India
}

Copyright $\subset 2017$ by authors, all rights reserved. Authors agree that this article remains permanently open access under the terms of the Creative Commons Attribution License 4.0 International License

\begin{abstract}
The aim of this article is to evaluate the impact of postprandial hyperglycemia in patients with type 2 diabetes mellitus (T2DM). Postprandial hyperglycemia is a major determinant in overall glycemic control. Diabetic mellitus is an endocrine disorder steadily increasing worldwide, particularly in the developing countries like India. Diabetic patients are at high risk of cardiovascular events and mealtime plasma glucose fluctuations are important cardiovascular risk factors in type 2 diabetic patients. Diabetes is also one of the most important risk factors for chronic kidney disease. For diabetic patients with chronic kidney disease (CKD), the risk of cardiovascular disease is even higher. CKD can impair the ability of the kidneys to metabolize drugs and as a consequence a dose adjustment or an extended dose interval is usually needed in CKD patients in order to keep an optimal safety/efficacy profile. Oral hypoglycemic agents like glinides and alpha glucosidase inhibitors do not require dose adjustments and hence can be used safely in patients with CKD. Oral treatment with Repaglinide has proven beneficial effect on cardiovascular risk factors. It is therefore very important to use pharmacological tools allowing keeping post-meal glucose oscillations within narrow range. Regimens that target both fasting and post meal glycemia are needed to achieve optimal glucose control to prevent microvascular and macrovascular complications.
\end{abstract}

Keywords Post Prandial Hyperglycemia, Cardiovascular Events, CKD, Glinides, Alpha Glucosidase Inhibitor

\section{Introduction}

Diabetes is a complex, chronic illness requiring continuous medical care with multifactorial risk reduction strategies beyond glycemic control. [1] As per International diabetes federation (IDF) data, in 2035 India will stand $2^{\text {nd }}$ in the world with a total of 109.0 million people suffering from diabetes. [2]

T2DM is a disorder characterized by insulin resistance and a progressive decline in pancreatic $\beta$-cell function associated with increasing hyperglycaemia. Defective $\beta$-cell function occurs early and can be detected in individuals with impaired fasting and/or post-prandial glucose levels. The UK Prospective Diabetes Study (UKPDS) indicated that by the time T2DM is diagnosed, individuals have already lost up to $50 \%$ of their $\beta$-cell function. [3]

The overall amount of ingested glucose absorbed by the body does not change. There is decreased tissue glucose clearance and glucose oxidation, with increased non-oxidative glycolysis, glycogen cycling, and glucose uptake in alternative tissues throughout the body.

The net result is that more glucose (endogenous + ingested) enters the circulation at a faster rate than the body can remove it, resulting in prolonged elevations of plasma glucose. [4]

Postprandial hyperglycaemia occurs when the multiple homeostatic mechanisms that minimize glucose fluctuations and restore normal glucose levels following a meal are blunted.

The degree of postprandial hyperglycaemia is primarily due to reduced suppression of hepatic glucose production. [5]

In individuals with impaired glucose tolerance the degree of glycemia $2 \mathrm{~h}$ after a glucose challenge is a stronger predictor of cardiovascular disease than fasting glycemia. Acute fluctuations in glycemia can produce significant alterations in normal homeostasis, such as those of endothelial dysfunction and increased inflammation. [6]

Diabetes is a major cause of CKD and pre-diabetes accompanies increased prevalence of CKD as well. For the National Health and Nutrition Examination Survey (NHANES) study, it was reported that $39.6 \%$ of people with diagnosed diabetes and $41.7 \%$ with undiagnosed diabetes had CKD; $17.7 \%$ with pre-diabetes and $10.6 \%$ without any kind of diabetes had CKD. [7]

Postprandial hyperglycemia (PPHG) has been linked to cardiovascular morbidity and mortality even when HbAlc 
values are in the non-diabetic range, whereas elevated fasting plasma glucose (FPG) concentrations are not independently associated with increased cardiovascular disease (CVD) risk. [8]

The achievement of a good glycaemic control is one of the cornerstones for preventing and delaying progression of microvascular and macrovascular complications. [9]

The objective of this review article was to enlighten about the significant contribution of PPHG to be a major determinant in increased HbAlc. Carbohydrate is a major component of Indian diet and hence becomes a front-runner in after meal glucose excursions. After extensive literature search, it was convened that treating PPHG can improve in decreasing $\mathrm{HbA} 1 \mathrm{c}$ at around $70 \%$, thus making it an essential factor to be considered while determining the treatment regimen in individuals suffering from T2DM. Nephropathy is one of the associated risk factor in diabetes. Available oral hypoglycemic agents have limitations of either being contraindicated or of dose reduction in individuals with compromised renal function.

Apprising the use of drugs (Glinides, Alpha glucosidase inhibitors etc.) which can contribute in reducing $\mathrm{HbAlc}$ in individuals by targeting PPHG and without any dose reduction for those with renal impairment can prove to be a new armamentarium of treating diabetes in majority population.

\section{Significant Contribution of FPG \& PPHG to Hba1c Level}

In patients with Type 2 diabetes, $\mathrm{HbAlc}$ is correlated with early postlunch/late postlunch glucose levels and less with fasting glucose levels. The early and late postlunch glucose values are predictive for poor diabetes control, indicating that PPHG is a major determinant in overall glycaemic control. [4]

Monnier et al. found that the relative contribution of PPHG was higher $(70 \%)$ in patients with fairly good control of diabetes ( $\mathrm{HbA} 1 \mathrm{c}<7.3 \%)$ and decreased progressively $(30 \%)$ with worsening diabetes (HbAlc $>10.2 \%)$. Decreases in PPHG accounted for nearly twice the decrease in HbA1c compared with decreases in FPG (Figure 1). [10]

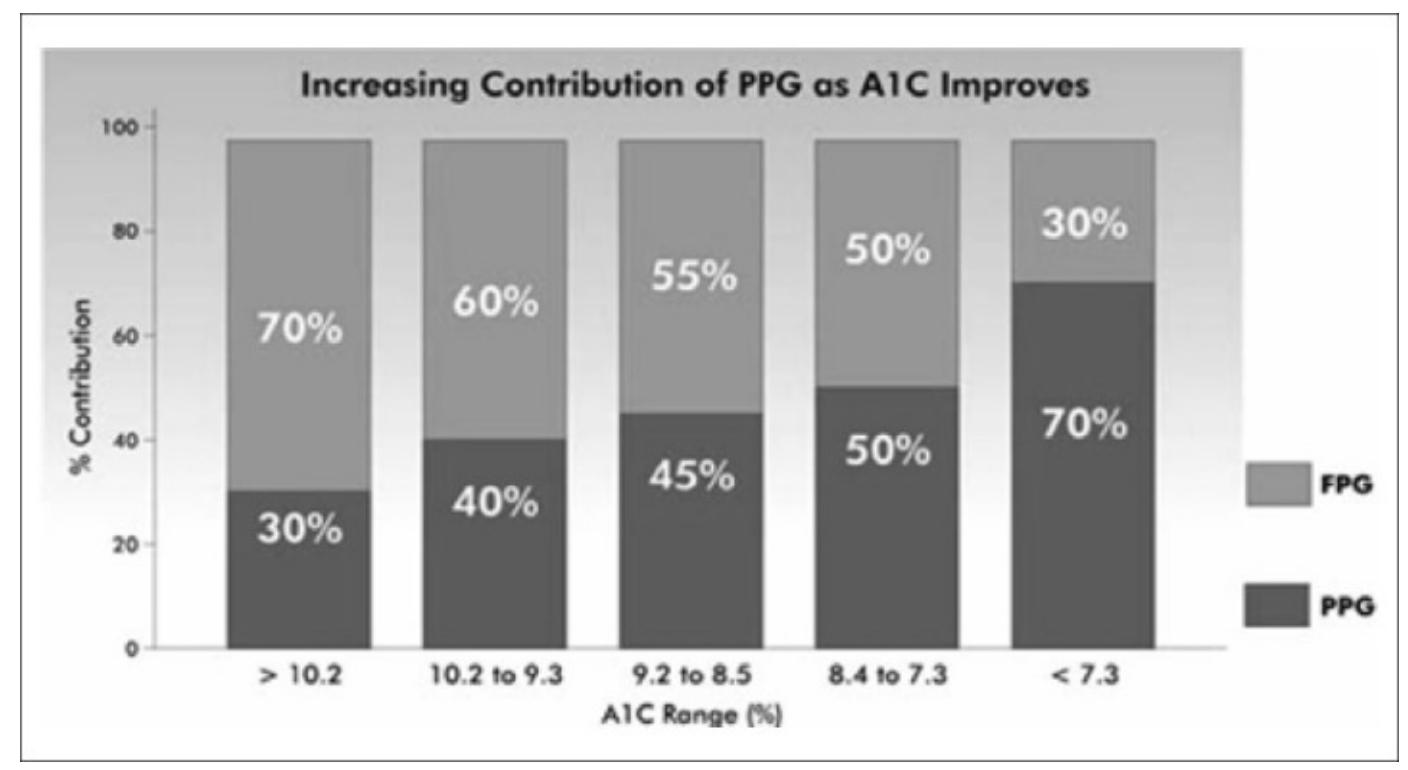

Figure 1. Contribution of PPHG in improving HbAlc compared to FPG [10]

Table 1. Morbidity and mortality related to post challenge and postprandial hyperglycemia

\begin{tabular}{|c|l|l|}
\hline Study & \multicolumn{1}{|c|}{ Patients } & \multicolumn{1}{|c|}{ Key findings } \\
\hline DECODE study & $\begin{array}{l}\text { 10 prospective studies among 15,388 men and } \\
7126 \text { women not previously diagnosed with } \\
\text { diabetes }\end{array}$ & $\begin{array}{l}\text { 2-hour blood glucose levels following 75-g OGTT better } \\
\text { predictor of all-cause and cardiovascular deaths than FBG } \\
\text { levels }\end{array}$ \\
\hline Chicago Heart association & $\begin{array}{l}12,220 \text { men with diabetes or asymptomatic } \\
\text { hyperglycemia }\end{array}$ & $\begin{array}{l}\text { Increased risk of CVD mortality with higher post load } \\
\text { glucose level (after 50-g OGTT) }\end{array}$ \\
\hline Temelkova-Kurktschiev et al & 582 men and women at risk for type 2 diabetes & $\begin{array}{l}\text { 2-hour blood glucose levels and spikes more strongly } \\
\text { associated with CIMT than FPG of HbA1c }\end{array}$ \\
\hline Diabetes Intervention Study & $\begin{array}{l}1139 \text { men and women with newly diagnosed type } \\
\text { 2 diabetes }\end{array}$ & $\begin{array}{l}\text { PPHG, but not FPG, significant risk factor for all MI and } \\
\text { mortality }\end{array}$ \\
\hline $\begin{array}{c}\text { Campanian Postprandial } \\
\text { Hyperglycemia Study }\end{array}$ & $\begin{array}{l}\text { 93 men and 82 women with type 2 diabetes not } \\
\text { previously drug-treated }\end{array}$ & $\begin{array}{l}\text { Reduction of PPHG, but not FPG, associated with } \\
\text { reductions in CIMT }\end{array}$ \\
\hline
\end{tabular}


PPHG has been identified as an independent risk factor for CVD in patients with or without diagnosed diabetes, suggesting that PPHG may be a better predictor of risk than is FPG or HbAlc alone (Table 1). [8]

DECODE, Diabetes Epidemiology: Collaborative Analysis of Diagnostic Criteria in Europe; OGTT, oral glucose tolerance test; FBG, fasting blood glucose; CVD, cardiovascular disease; CIMT, carotid intima-medial thickness; HbA1c, glycosylated hemoglobin; MI, myocardial infarction, FPG, fasting plasma glucose. [8]

Postprandial hyperglycemia (1) is an independent risk factor for CVD; (2) increases earlier and faster than fasting plasma glucose levels; and (3) contributes more to HbAlc levels than fasting hyperglycemia when $\mathrm{HbA} 1 \mathrm{c}$ levels approach target values and, therefore, is the rate-limiting factor for achieving optimal glycemic control. [11]

Many individuals with $\mathrm{HbA1c}$ levels within the normal range $(<6.0 \%)$ will have abnormally increased postprandial plasma glucose levels $(\geq 140 \mathrm{mg} / \mathrm{dl}$ ) while still having normal $(<100 \mathrm{mg} / \mathrm{dl})$ fasting plasma glucose levels. Thus, even individuals with normal HbAlc levels and normal fasting plasma glucose levels are at risk for cardiovascular disease. [11]

\subsection{PPHG \& Its Complications}

Since 1997, over 15 observational studies have been published showing that elevated postprandial glucose values, even in the high non-diabetic impaired glucose tolerance (IGT) range, contribute to an approximately 3 fold increase in the risk of developing coronary heart disease or a cardiovascular (CV) event. [12] PPHG, but not FPG, is a significant predictor of subsequent myocardial infarction (MI) and death in patients with newly diagnosed type 2 diabetes. [8]

Metabolic syndrome (MetS) is a clustering of hyperglycemia/insulin resistance, obesity and dyslipidemia. [13] Underlying risk factors include T2DM and CVD. Major risk factors for developing MetS are physical inactivity and a diet high in fats and carbohydrates, contributing to the two central clinical features, i.e. central obesity and insulin resistance (IR). [14] Excess adipose tissue releases excess fatty acids and a variety of adipokines that seemingly elicit metabolic risk factors that predispose to both diabetes and CVD (Figure 2). [7]

MetS (obesity, dyslipidemia, hypertension and microalbuminuria) is seen in $10 \%$ of subjects with normal glucose tolerance (NGT), $50 \%$ of those with IGT and $80 \%$ of patients with Type 2 diabetes, severely contributes to the burden of macrovascular disease. [4]

A meta-analysis of 20 studies in over 80,000 subjects found a progressive relationship between FPG and 2-h glucose and CVD mortality with no real threshold. Known risk factors for atherosclerosis were more strongly associated with 2-h glucose levels than with either HbAlc or FPG. Epidemiological data show that 2-h plasma glucose is a risk indicator not only in patients with Type 2 diabetes but also in subjects with IGT. [4]

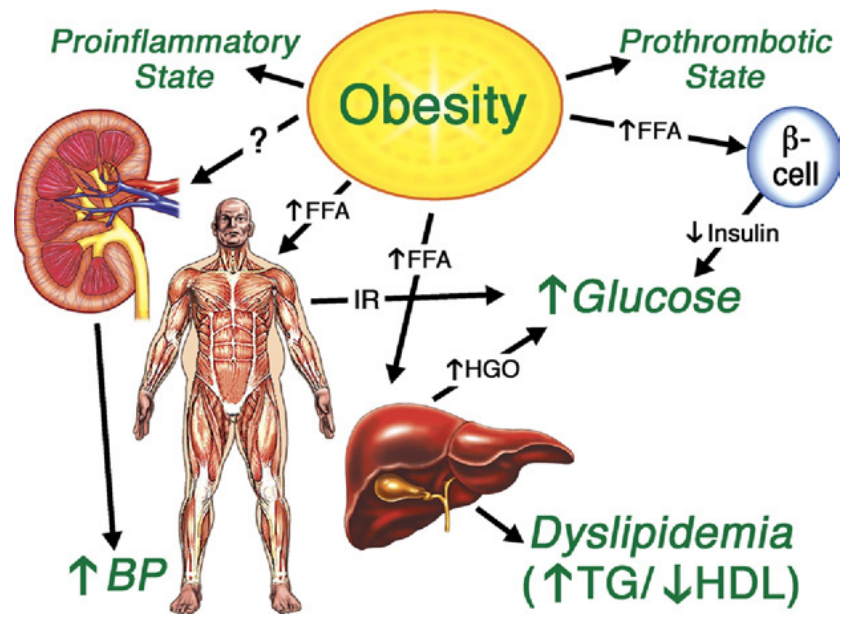

Figure 2. Metabolic Pathways Underlying Pre-Diabetes and Metabolic Syndrome (FFA: Free fatty acids, IR: Insulin resistance, HGO: Hepatic glucose output, TG: Triglycerides, HDL: High density lipoprotein, BP: Blood pressure). [7]

The harmful effects of PPHG are mediated by protein kinase C (PKC), advanced glycation end products (AGE), Polyol and Hexoseamine pathway and include as (a) PPHG and CV Mortality (b) PPHG and oxidative stress, inflammation, and endothelial dysfunction (c) PPHG and carotid intima media thickness (CIMT) (d) PPHG and micro-vascular complications (e) PPHG and cognitive function (f) PPHG and cancer. [10]

Various mechanisms responsible for triggering the cardiovascular complications due to PPHG are postulated in Table 2.

Table 2. Mechanisms involving postprandial hyperglycemia and CV risk [10]

\begin{tabular}{|l|}
\hline Glucose auto-oxidation increased (oxidative stress) \\
\hline Endothelial function disordered (reduced nitrous oxide (NO) release) \\
\hline Low-grade inflammation increased \\
\hline Blood coagulation increased \\
\hline Fibrinolysis reduced \\
\hline Plaque stability decreased \\
\hline $\begin{array}{l}\text { Triglyceride-rich lipoproteins and low density lipoprotein (LDL) } \\
\text { removal reduced }\end{array}$ \\
\hline HDL cholesterol catabolism increased \\
\hline $\begin{array}{l}\text { Free fatty acid decrease and early phase insulin secretion reduced and } \\
\text { insulin resistance increased }\end{array}$ \\
\hline
\end{tabular}

\subsubsection{PPHG \& Major Vascular Disorders}

PPHG is significantly linked to major vascular disorders. Inhibition of lipoprotein lipase activity due to impaired insulin action on adipocytes and an increase of exogenous lipoproteins due to overeating are considered to be the underlying causes of postprandial hyperlipidemia (PPHL). PPHL may trigger progression of arteriosclerosis with the accumulation of chylomicron remnants in the vessel walls. [15]

Postprandial hyperglycaemia typically is an early phenomenon, whereas the triglyceride excursions remain elevated for a prolonged period of time. Both may via separate routes promote the development of cardiovascular disease (Figure 3). [4] 


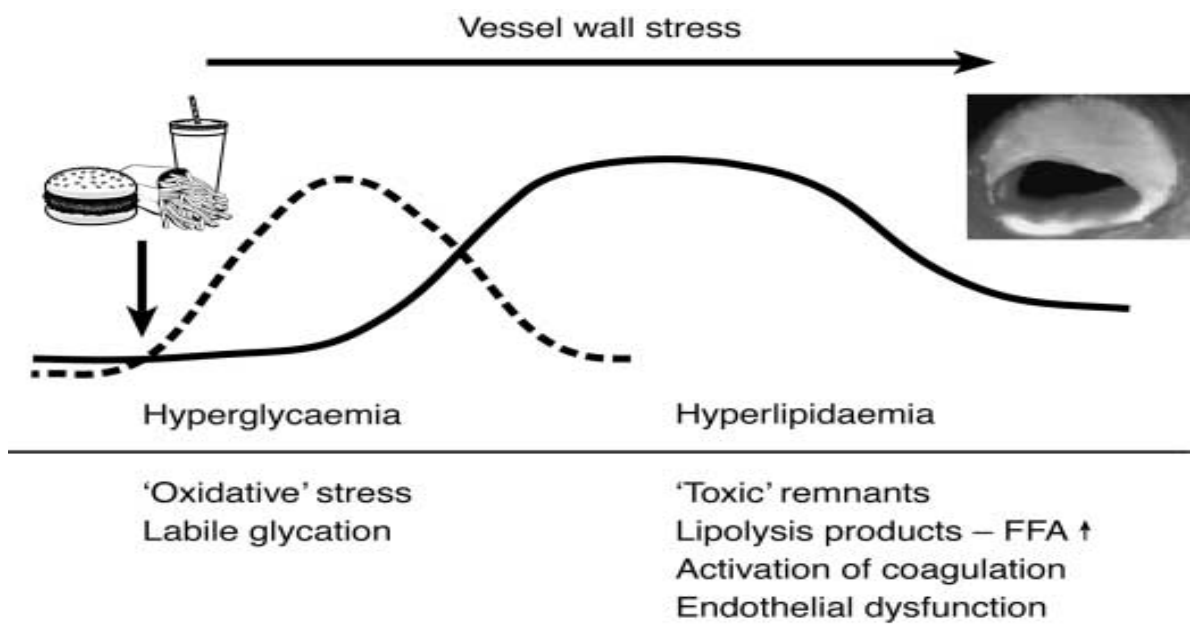

Figure 3. Time course of postprandial hyperglycaemia and hypertriglyceridaemia following a mixed meal. [4]

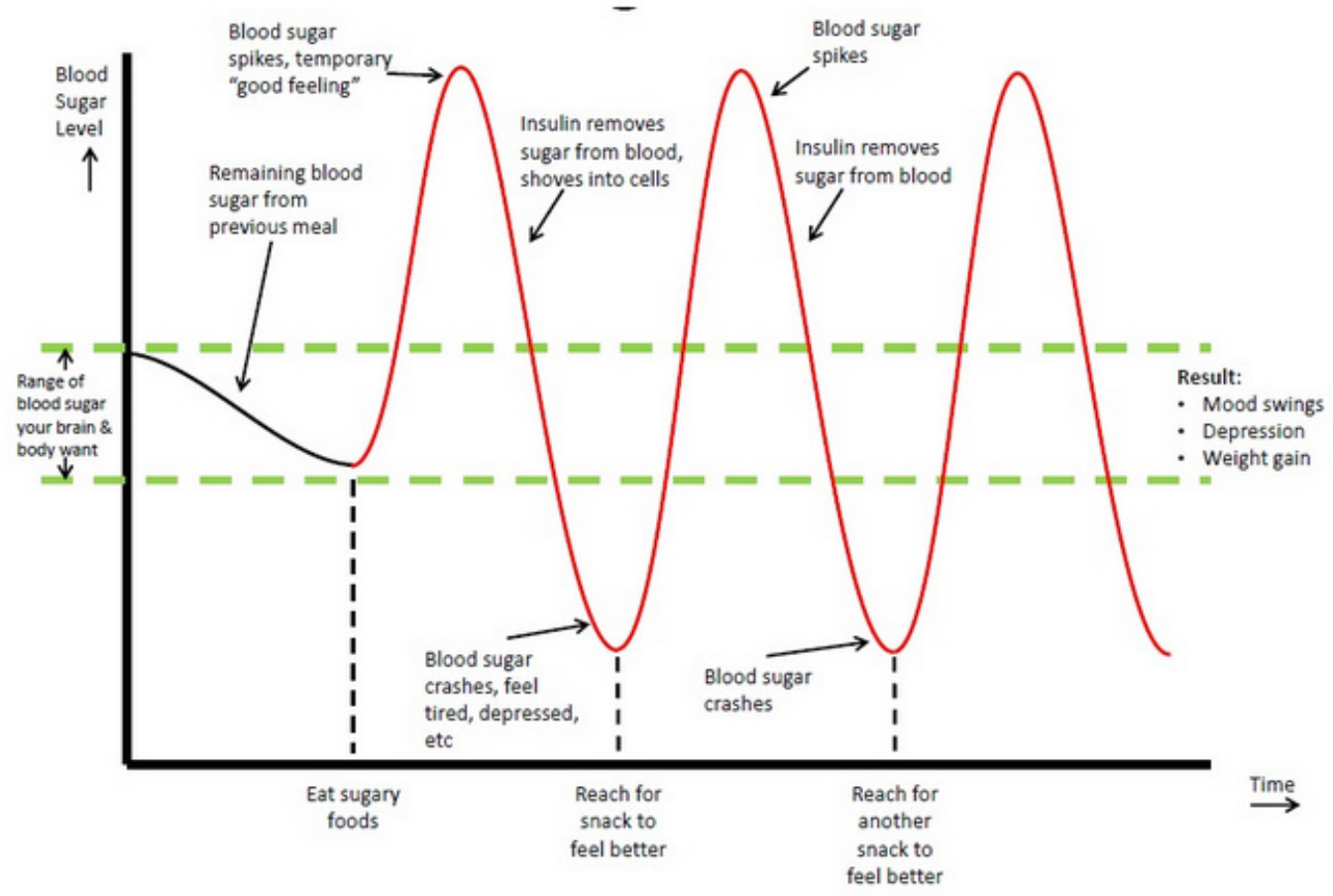

Figure 4. Post meal glucose excrusions and its effects. [14]

\subsubsection{Sugar Spikes \& Its Post Meal Impact}

Body wants to maintain a mid range blood sugar level. In this effort, a spike in blood sugar will cause your pancreas to start pumping insulin into your system to compensate. One of insulin's responsibilities is to stabilize blood sugar. [16]

Pancreas has a strong tendency to overestimate the amount of insulin it needs to release, and the result is that too much glucose is removed from your blood. This results in a blood sugar crash, or very low blood sugar levels. This is also known as hypoglycemia (Figure 4). [16]

\subsubsection{Cellular Mechanisms Triggered by PPHG and/or PPHL}

(1) Both

$$
\text { postprandial hyperglycaemia }
$$

hypertriglyceridaemia are accompanied by oxidative stress, which in turn causes endothelial dysfunction and eventually atherosclerosis (2) acute increases in glucose stimulate superoxide production at the mitochondrial level in endothelial cells, which in turn leads to endothelial dysfunction and atherosclerosis (3) rapid increases in glucose and lipid levels after ingestion of a meal are also likely to trigger carbonyl stress which, either independently or by potentiation of oxidative stress, contributes to the development of both microvascular and macrovascular complications. [4]

In a study conducted by Kapur et al, glucose, insulin, and triglyceride levels averaged over all meals for all volunteers at each time point were recorded (figure 5). It was noted that glucose and insulin peaked at the $30 \mathrm{~min}$ postprandial time 
point and then declined. Triglycerides showed a more gradual increase and tended to be still rising at the $2.5 \mathrm{~h}$ time point. [17]

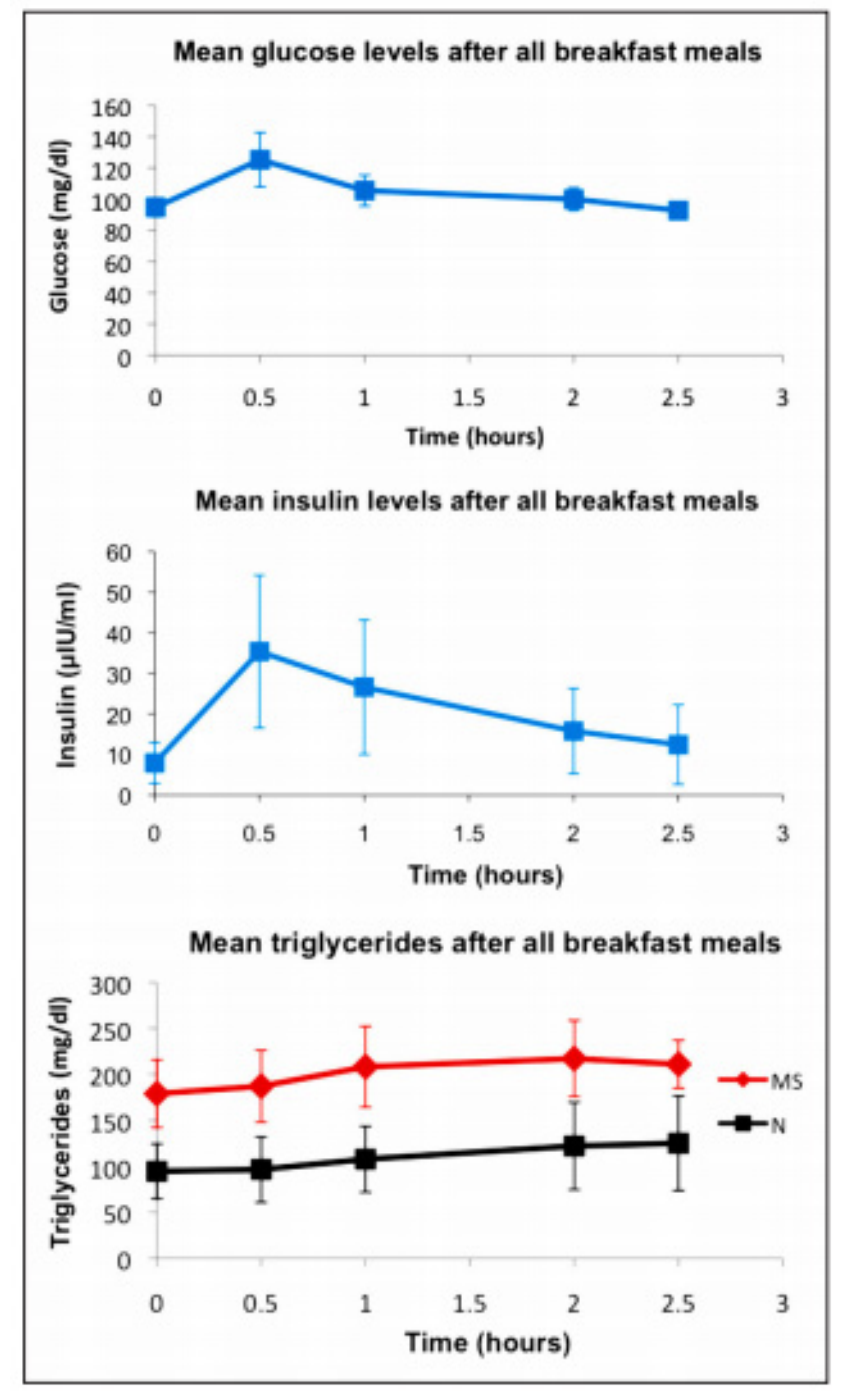

Figure 5. Glucose, insulin, and triglyceride levels (including all subjects, mean value \pm standard deviation) for all meals at each time point. [17]

Both hyperglycaemia and hypertriglyceridaemia can trigger free radical production and therefore may contribute to the development of complications. Correcting postprandial hyperglycaemia and dyslipidemia forms an important part of the strategy for the prevention and management of complications in patients with Type 2 diabetes. [4]

\subsection{Cardiovascular Impact of Oral Hypoglycemic Agents}

Diabetes Mellitus (DM) with poor glycemic control is one of the leading causes for cardiovascular mortality in diabetic patients. [18]

Metformin: It is a first-line therapy for patients with type 2 diabetes but contraindicated in individuals with severe heart failure (HF) classes III-IV [as per New York Heart
Association, NYHA] due to lactic acidosis associated mortality rate of $50 \%$. [3]

Sulfonylureas (SU): Acute hypoglycaemia induced by sulfonylureas, may trigger ischemia and cardiovascular events. In early 1970, the report of the University Group Diabetes Program (UGDP) suggested that Tolbutamide therapy was no more effective than diet alone and was associated with an increase in cardiovascular toxicity. Garratt et al demonstrated increased early mortality in 67 persons taking the sulfonylurea Glyburide vs. 118 using insulin or lifestyle therapy alone. [3]

Several observational studies have retrospectively compared Metformin and SU monotherapy; all found worryingly increased risk ( $21 \%$ to $70 \%)$ of cardiovascular mortality associated with SU use. [19]

Thiazolidinediones (TZD): A retrospective analysis of data from $>2$ 2, 25, 000 patients concluded that the use of Rosiglitazone was associated with an increased risk of stroke, heart failure, and all-cause mortality in patients aged 65 years or older. Clinicians are most likely to see oedema as a consequence of TZD therapy when either of the TZDs is used in combination with insulin. Therefore, patients with NYHA functional class III or IV heart failure should not receive TZDs. [3]

DPP4 Inhibitors: Three trials, EXAMINE (EXamination of cArdiovascular outcoMes with alogliptIN versus standard of carE in patients with T2DM and ACS), SAVOR-TIMI (Saxagliptin Assessment of Vascular Outcomes Recorded in Patients with Diabetes Mellitus-Thrombolysis in Myocardial Infarction) and TECOS (Trial to Evaluate Cardiovascular Outcomes after Treatment with Sitagliptin) suggest that DPP-4 inhibitors are basically safe from a cardiovascular standpoint but also do not improve cardiovascular endpoints at least in the short term. [3]

\subsection{Diabetes \& Chronic Kidney Disease (CKD)}

CKD is a worldwide public health problem that affects millions of people from all racial and ethnic groups. Diabetes mellitus is the leading cause of CKD, and the rapidly increasing prevalence of diabetes worldwide virtually assures that the proportion of CKD attributable to diabetes will continue to rise. [9]

Blood sugar control in those with CKD adds another level of complexity. Consequences of hypoglycemia, which in turn can cause injury, myocardial infarction, seizure, stroke or death, are greatest in those who are frail and elderly, with erratic eating habits, on insulin and sulfonylureas, and with CKD. [20]

\subsubsection{Factors Related to Drug Pharmacokinetics in Ckd Population}

All aspects of drug pharmacokinetics (absorption, distribution, metabolism and excretion) can be influenced by CKD. [20]

In CKD, gastric acidity is usually altered due to the presence of uraemic gastritis or by the ingestion of 
medications with anti acid effects (e.g. phosphate binders and proton pump inhibitors). Moreover, gastric emptying is often delayed in these patients when they also have diabetes, quite often due to diabetic and/or uremic gastroparesis. [20]

When extracellular fluids are increased, such as in hypervolaemic or oedematous CKD patients, the increase in volume of distribution $(\mathrm{Vd})$ leads to a reduction in serum levels of the drug. Both CKD and diabetes might be associated with hypo-albuminaemia and CKD may also significantly impair the capacity of plasma protein to bind and transport drugs. [20]

CKD can impair the ability of the kidneys to metabolize drugs and, as a consequence, in CKD patients an increased half-life has been observed even for drugs not undergoing renal excretion (be it tubular or glomerular). [20]

A dose adjustment or an extended dose interval is usually needed in CKD patients in order to keep an optimal safety/efficacy profile as depicted in Table 3. [20]

Table 3. Glucose lowering efficacy of antihyperglycemic agents in renal failure

\begin{tabular}{|c|c|c|c|c|c|c|}
\hline Generic Name & $\begin{array}{l}\text { HbA1c } \\
\text { Drop }\end{array}$ & Hypoglycemia & $\begin{array}{l}\text { Weight } \\
\text { Gain }\end{array}$ & Initial Dose & Maximum Dose & Use in Renal failure \\
\hline Biguanides & $1.0-1.5$ & No & No & & & \multirow{2}{*}{$\begin{array}{l}\text { Contraindicated when } \\
\text { creatinine clearance is } \\
60 \mathrm{ml} / \mathrm{min} \text { because of } \\
\text { the risk for lactic } \\
\text { acidosis }\end{array}$} \\
\hline Metformin & & & & $250 \mathrm{mg}$ twice daily & $\begin{array}{c}850 \mathrm{mg} \text { three times a } \\
\text { day }\end{array}$ & \\
\hline Thiazolidinediones & $1.0-1.5$ & No & Yes & & & \multirow{3}{*}{$\begin{array}{l}\text { Metabolism not } \\
\text { affected in renal } \\
\text { failure, but fluid } \\
\text { retention may be a } \\
\text { problem, with } \\
\text { heightened risk for } \\
\text { congestive heart } \\
\text { failure }\end{array}$} \\
\hline Rosiglitazone & & & & $4 \mathrm{mg} / \mathrm{d}$ & $\begin{array}{c}8 \mathrm{mg} / \mathrm{d} \text { or } 4 \mathrm{mg} \text { twice } \\
\text { daily }\end{array}$ & \\
\hline Pioglitazone & & & & $15 \mathrm{mg} / \mathrm{d}$ & $45 \mathrm{mg} / \mathrm{d}$ & \\
\hline Sulfonylureas & $1.0-1.5$ & Yes & Yes & & & \multirow{8}{*}{$\begin{array}{l}\text { The metabolism of all } \\
\text { sulfonylureas is } \\
\text { affected by renal } \\
\text { failure; this will } \\
\text { initially require } \\
\text { decreases in dosages, } \\
\text { and eventually } \\
\text { avoidance of these } \\
\text { agents }\end{array}$} \\
\hline Glyburide & & & & $2.5-5 \mathrm{mg} / \mathrm{d}$ & $10 \mathrm{mg}$ twice daily & \\
\hline Gliclazide & & & & $\begin{array}{c}40-80 \mathrm{mg} \text { twice } \\
\text { daily or MR } 30 \mathrm{mg}\end{array}$ & $\begin{array}{l}160 \mathrm{mg} \text { twice daily or } \\
\text { MR } 120 \mathrm{mg} / \mathrm{d}\end{array}$ & \\
\hline Glimepiride & & & & $1 \mathrm{mg} / \mathrm{d}$ & $8 \mathrm{mg} / \mathrm{d}$ & \\
\hline Glipizide & & & & $\begin{array}{c}5 \mathrm{mg} / \mathrm{d} \text { or XL } 5 \\
\mathrm{mg} / \mathrm{d}\end{array}$ & $\begin{array}{l}20 \mathrm{mg} \text { twice daily or } \\
\text { XL } 20 \mathrm{mg} / \mathrm{d}\end{array}$ & \\
\hline Tolbutamide & & & & $500 \mathrm{mg}$ twice daily & $\begin{array}{l}500 \text { mg four times a } \\
\text { day }\end{array}$ & \\
\hline Chlorpropamide & & & & $100 \mathrm{mg} / \mathrm{d}$ & $500 \mathrm{mg} / \mathrm{d}$ & \\
\hline Acetohexamide & & & & $250 \mathrm{mg} / \mathrm{d}$ & $\begin{array}{l}500 \mathrm{mg} \text { three times a } \\
\text { day }\end{array}$ & \\
\hline Meglitinides & $1.0-1.5$ & Yes & Yes & & & \multirow{3}{*}{$\begin{array}{l}\text { Can be used in the } \\
\text { presence of renal } \\
\text { failure as the } \\
\text { pharmacokinetics are } \\
\text { unaffected }\end{array}$} \\
\hline Repaglinide & & & & $\begin{array}{l}0.5 \mathrm{mg} \text { three times a } \\
\text { day }\end{array}$ & $4 \mathrm{mg}$ three times a day & \\
\hline nateglinide & & & & $\begin{array}{c}120 \mathrm{mg} \text { three times } \\
\text { a day }\end{array}$ & $\begin{array}{l}180 \mathrm{mg} \text { three times a } \\
\text { day }\end{array}$ & \\
\hline$\alpha$-Glucosidase inhibitors & $0.5-1.0$ & No & No & & & \multirow{3}{*}{$\begin{array}{l}\text { Contraindicated in } \\
\text { renal failure }\end{array}$} \\
\hline acarbose & & & & $\begin{array}{c}25 \mathrm{mg} \text { three times a } \\
\text { day }\end{array}$ & $\begin{array}{c}100 \mathrm{mg} \text { three times a } \\
\text { day }\end{array}$ & \\
\hline miglitol & & & & $\begin{array}{c}25 \mathrm{mg} \text { three times a } \\
\text { day }\end{array}$ & $\begin{array}{c}100 \mathrm{mg} \text { three times a } \\
\text { day }\end{array}$ & \\
\hline
\end{tabular}




\subsubsection{Renal Safety of Antihyperglycemic Agents in CKD}

Metformin: Metformin is contraindicated in renal failure because of the associated risk for lactic acidosis. In CKD-4 patients with unstable kidney function, it is advisable to (temporarily) withhold the drug, as in these patients small absolute increases in GFR (glomerular filtration rate) might result in large variations in serum concentration of Metformin. [9]

Thiazolidinediones: Drug of this class is unaffected by renal failure. Nevertheless, a higher risk of congestive heart failure due to chronic fluid overload might be hypothesized, particularly in CKD patients with cardiac comorbidities taking Pioglitazone. [9]

Sulfonylureas: Sulfonylureas and their metabolites are renally cleared. [20] Progressive falls in kidney function result in decreased clearances of the sulfonylureas or their active metabolites necessitating a decrease in drug dosing to avoid hypoglycemia. [9]

Hypoglycemia is greatly increased with glimepiride and glyburide with GFR $<60 \mathrm{ml} / \mathrm{min} / 1.73 \mathrm{~m}^{2}$ due to the presence of two active metabolites cleared in part by the kidney. [20]

Role of Meglitinide analogs in CKD: Hypoglycemia has not been demonstrated to increase substantially with progressive falls in GFR when treated with Repaglinide. [21] The nonsulfonylurea insulin secretagogues repaglinide and nateglinide can be used in renal failure without dose adjustments. [20]

No relationship have been found between the degree of renal impairment and the risk of hypoglycemia in patients treated with repaglinide, including those with severe or even extreme degrees of renal impairment. [22]
A multinational, open-label study comprising of a 6-week run-in period, continuing prestudy antidiabetic medication, followed by a titration period (1-4 weeks) and a 3-month maintenance period was conducted. Patients with normal renal function $(\mathrm{n}=151)$ and various degrees of renal impairment $(n=130)$ were treated with repaglinide (maximal dose of $4 \mathrm{mg}$, three times daily). Safety and efficacy assessments were performed at baseline (end of run-in) and at the end of study treatment.

$48 \%$ Patients with normal renal function had been titrated to the highest allowed repaglinide dose (4 $\mathrm{mg}$ with meals) by the end of the study. Similar proportions of the mild and moderate renal impairment groups also reached this dose (48 and $41 \%$, respectively), whereas in the severe and extreme renal impairment groups only 33 and $30 \%$ of patients, respectively, reached the highest dose level (Figure 6). [23]

Role of $\alpha$-glucosidase inhibitors (AGI) in CKD: Voglibose, an alpha glucosidase inhibitor (AGI) is useful in elderly patients and in those with mild to moderate renal function impairments when other anti diabetic agents are contraindicated. It potentially provides another therapeutic option for patients with Type 2 diabetes mellitus in which glycaemic control is inadequate, despite diet alone or with pharmacological therapy with sulfonylurea and biguanide. [24]

The inhibitory activity of voglibose on maltose and sucrose is 190-270 times higher than that of acarbose and it is 100 times higher than that of miglitol. Voglibose improves post-prandial hyperglycaemia and fasting blood sugar in NIDDM patients who are poorly controlled, despite strict diet control and taking other oral hypoglycaemic agents. [24]

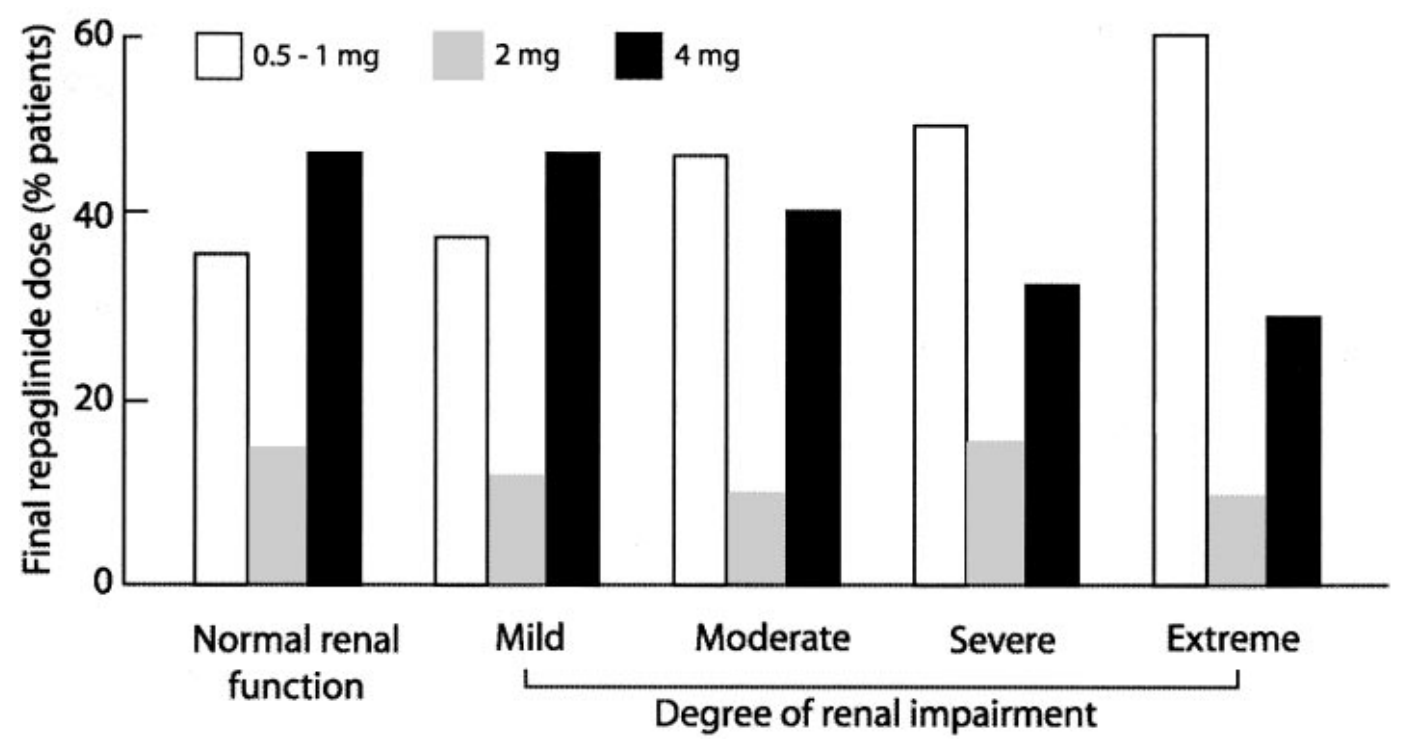

Figure 6. Repaglinide in renal impaired patients [21] 


\section{Discussion}

Postprandial plasma glucose levels increase earlier and at a greater rate than fasting plasma glucose levels as $\mathrm{HbAlc}$ levels increase from 4.0 to $7.0 \%$ and are the rate-limiting factor preventing achievement of optimal glycemic control. [11]

PPHG control is important not only for regulating glycemia, but also because reducing postprandial hyperglycemia may mitigate cardiovascular risks. [5]

PPHG should be considered as a marker for the cluster of metabolic abnormalities responsible for the development of long-term complications in patients with Type 2 diabetes. As per American Diabetes Association, in order to reduce HbA1c values maximally, assessments of both pre- and postprandial glucose levels are necessary. [4]

Repaglinide is absorbed from the gastrointestinal tract and metabolized in the liver by oxidation and conjugation with glucuronic acid. [13] Hemodialysis does not significantly affect repaglinide clearance. [25] Less than $10 \%$ of its metabolites are eliminated renally. [26]

Repaglinide (Glinide) may be used in type 2 diabetic patients even in CKD stages 4 and 5 without dose reduction and for patients with normal renal function, without compromising safety or loss of efficacy. [15, 22] Voglibose (AGI) also has the advantage of using in those with mild to moderate CKD without dose reduction. [24]

Thus amongst the oral hypoglycemic agents, certain drugs can be considered more efficacious in management of PPHG like Repaglinide, Voglibose. These drugs also have the advantage of lesser chances of hypoglycemia as they are short acting. Moreover since many diabetes patients have concomitant CKD, both these drugs are considered reasonably safe despite the compromised renal function.

Since PPHG is responsible for most of the complications in diabetes patients, it is prudent and pragmatic to focus on normalizing post prandial sugar spikes.

\section{Conclusions}

PPHG is the major determinant of HbAlc levels. Reduction in PPHG significantly reduces HbA1c levels in T2DM. Current treatment guidelines for type 2 diabetes mellitus emphasize the importance of controlling postprandial hyperglycemia to optimize glycemic control, which may result in a lower risk of cardiovascular morbidity and mortality.

\section{REFERENCES}

[1] American Diabetes Association Standards of Medical Care in Diabetes 2017. Diabetes Care 2017;40 (Suppl. 1):S1-S2

[2] International Diabetes Federation, IDF Diabetes Atlas; $7^{\text {th }}$
Edition, 2015

[3] R. Kumar, D. M. Kerins, T. Walther; Cardiovascular safety of anti-diabetic drugs. Eur Heart J Cardiovasc Pharmacother 2016; 2 (1): 32-43

[4] R. J. Heine, B. Balkau, A. Ceriello, S. Del Prato, E. S. Horton and M-R. Taskinen. What does postprandial hyperglycaemia mean? Diabet. Med. 21, 208-213 (2004)

[5] Gerich J. Pathogenesis and management of postprandial hyperglycemia: role of incretin-based therapies. Int J Gen Med. 2013 Dec 4; 6: 877-95.

[6] Ceriello A, Kilpatrick ES. Glycemic variability: both sides of the story. Diabetes Care. 2013 Aug; 36 Suppl 2:S272-5.

[7] Grundy SM. Pre-diabetes, metabolic syndrome, and cardiovascular risk. J Am Coll Cardiol. 2012 Feb 14; 59 (7):635-43.

[8] Hurel SJ, Mohan V. Clinical decision making: managing postprandial hyperglycemia. J Assoc Physicians India. 2006 Nov; 54:871-6.

[9] Arnouts P, Bolignano D, Nistor I, Bilo H, Gnudi L, Heaf J, van Biesen W. Glucose-lowering drugs in patients with chronic kidney disease: a narrative review on pharmacokinetic properties. Nephrol Dial Transplant. 2014 Jul; 29(7):1284-300.

[10] SK Singh. Post-prandial hyperglycemia. Indian J Endocrinol Metab. 2012 Dec; 16 (Suppl 2): S245-S247.

[11] John E. Gerich, and Hans J. Woerle. Clinical Significance of Postprandial Hyperglycemia. Drug Dev. Res. 67:587-590, 2006.

[12] Standl E, Schnell O, Ceriello A. Postprandial hyperglycemia and glycemic variability: should we care? Diabetes Care, 2011 May; 34 Suppl 2:S120-7.

[13] Paul L. Huang. A comprehensive definition for metabolic syndrome. Dis Model Mech. 2009 May-Jun; 2(5-6): 231-237.

[14] O'Neill S, O'Driscoll L. Metabolic syndrome: a closer look at the growing epidemic and its associated pathologies. Obes Rev. 2015 Jan; 16(1):1-12.

[15] Kojima Y, Kaga H, Hayashi S, Kitazawa T, Iimura Y, Ohno M, Yoshitsugu M, Fujiwara M, Hiyoshi T. Comparison between sitagliptin and nateglinide on postprandial lipid levels: The STANDARD study. World J Diabetes. 2013 Feb 15;4(1):8-13.

[16] The Blood Sugar Rollercoaster. Viewed and dated on Jun 02, 2017

http://www.nutritiontotheedge.com/how-blood-sugar-affectsyour-health-and-energy/

[17] Kapur S, Groves MN, Zava DT, Kapur S. Postprandial insulin and triglycerides after different breakfast meal challenges: use of finger stick capillary dried blood spots to study postprandial dysmetabolism. J Diabetes Sci Technol. 2010 Mar 1; 4(2):236-43.

[18] Moodahadu LS, Dhall R, Zargar AH, Bangera S, Ramani L, Katipally R. Tight glycemic control and cardiovascular effects in type 2 diabetic patients. Heart Views. 2014 Oct-Dec; 15(4):111-20.

[19] Mick Dwyer. Time to be cautious about prescribing 
sulfonylureas? Br J Gen Pract. 2015 Feb; 65(631): 93-94.

[20] Yale JF. Oral antihyperglycemic agents and renal disease: new agents, new concepts. J Am Soc Nephrol. 2005 Mar; 16 Suppl $1:$ S7-10.

[21] National Kidney Foundation. KDOQI Clinical Practice Guideline for Diabetes and CKD: 2012 update. Am J Kidney Dis. 2012; 60(5):850-886.

[22] Kelley DE, Bray GA, Pi-Sunyer FX, Klein S, Hill J, Miles J, Hollander P: Clinical efficacy of orlistat therapy in overweight and obese patients with insulin-treated type 2 diabetes. Diabetes Care 25:1033-1041, 2002.

[23] Hasslacher C; Multinational Repaglinide Renal Study Group.
Safety and efficacy of repaglinide in type 2 diabetic patients with and without impaired renal function. Diabetes Care. 2003 Mar; 26(3):886-91.

[24] Ajay S. Dabhi, Nikita R. Bhatt and Mohit J. Shah. Voglibose: An Alpha Glucosidase Inhibitor. J Clin Diagn Res. 2013 Dec; 7(12): 3023-3027.

[25] Marbury TC, Ruckle JL, Hatorp V, Andersen MP, Nielsen KK, Huang WC, Strange P. Pharmacokinetics of repaglinide in subjects with renal impairment. Clin Pharmacol Ther. 2000 Jan; 67(1):7-15.

[26] Nasri H and Kopaei M.R. Diabetes mellitus and renal failure: Prevention and management. J Res Med Sci. 2015 Nov; 20 (11): 1112-1120. 